\title{
ELABORAÇÃO DE BISCOITOS COM ADIÇÃO DE FARINHA DE CASCA DE BATATA (Solanum tuberosum L.)
}

\section{ELABORATION OF COOKIE WITH POTATO SKIN FLOUR (Solanum tuberosum L.)}

\author{
Tábata Tayara Garmus ${ }^{1}$; José Raniere Mazile Vidal Bezerra²; Maurício Rigo ${ }^{3}$ \\ Katielle Rosalva Voncik Córdova ${ }^{4}$ \\ 1, 2, ${ }^{3}$ Universidade Estadual do Centro-Oeste - UNICENTRO - Guarapuava-PR - Brasil \\ mauriciorigo@yahoo.com.br \\ ${ }^{4}$ Universidade Federal do Paraná - UFPR - Curitiba-PR - Brasil kvcordova@hotmail.com
}

\begin{abstract}
Resumo
Frente à importância do aproveitamento de resíduos na indústria, o presente artigo teve por objetivo estudar a elaboração de biscoito com adição de resíduos (farinha de casca de batata (Solanum tuberosum L.)). Foram preparadas três formulações (5, 10 e 20\%), variando-se a quantidade de farinha de casca de batata adicionada à formulação básica do biscoito. Nas análises físico-químicas da farinha de casca de batata foram obtidos valores 6,50\%; 7,34\%; 5,72; 2,49\%; 4,64\% e 2,46\% para umidade, cinzas, $\mathrm{pH}$, lipídios, teor de fibras e proteínas, respectivamente. $\mathrm{Na}$ análise sensorial, não houve diferença significativa no teste de aceitação nos níveis de significância de $1 \%$ e $5 \%$ entre as três formulações de biscoitos testadas. O biscoito com $5 \%$ de farinha de casca de batata em sua formulação apresentou valores de 10,2\%; 0,003\%; 6,71; 6,1\%; 3,1\%; 72,29\% e 8,3\% para umidade, cinzas, $\mathrm{pH}$, lipídios, teor de fibras bruta, carboidratos e proteínas respectivamente.
\end{abstract}

Palavras-chave: biscoito, farinha de casca de batata, resíduos.

\section{Introdução}

O biscoito é o produto obtido pela mistura, amassamento e cozimento de massa preparada com farinhas, amidos, fermentada ou não e outras substâncias alimentícias. Depois de ser transformada em várias receitas de pão, a mistura tradicional de água, farinha e fermento receberam novos ingredientes e transformaram-se em pizzas, pastéis, bolo, biscoitos, tortas, entre outros. Os principais ingredientes utilizados na elaboração de biscoitos são: farinha de trigo, gorduras, fermentos, açúcar ou adoçantes, sal e água, podendo também ser usados outros ingredientes como malte, suplementos enzimáticos, corantes, micronutrientes e outros (DASH, 1994).

A crescente preocupação com os impactos ambientais e o elevado índice de desperdício causado pelas indústrias de alimentos tem levado a busca de alternativas viáveis de aproveitamento 
desses resíduos para geração de novos produtos para consumo humano.

O aparecimento de resíduos, não só ocorre durante a escolha e seleção da matéria-prima cogitada, como também, nas diversas fases da fabricação. Os elementos residuais, constituídos por cascas e caroços, sementes, ramas, bagaços, etc., são fontes de proteínas, fibras, óleos e enzimas e podem ser empregados para utilização humana na elaboração de produtos com maior valor agregado, reservando-se os detritos para o fabrico de ração animal e adubos.

O aproveitamento dos subprodutos da agroindústria diminui os custos da produção e aumenta o aproveitamento do alimento além de reduzir o impacto que esses subprodutos podem causar ao serem descartados no ambiente.

A batata da espécie Solanum tuberosum L., comumente conhecida como batata inglesa, teve sua origem na atual fronteira entre Peru e Bolívia. A batata foi levada para a Espanha por volta de 1570, porém somente duzentos anos depois, tornou-se um alimento básico para os europeus (FILGUEIRA, 2000).

Segundo a Secretaria Municipal de Abastecimento de São Paulo - SEMAB (SÃO PAULO, 2003), a batata inglesa é rica em niacina, que mantém a saúde da pele, nervos e aparelho digestivo e potássio, que juntamente com o sódio contribui para a manutenção da concentração do líquido das células. A batata também é fonte importante de fósforo e vitaminas do grupo B. Como é pobre em proteínas e gorduras, este tubérculo é um alimento de fácil digestão e, por seu sabor, é utilizada em muitas preparações. Diante do exposto e da importância da cultura da batata, o presente trabalho tem como objetivo estudar a utilização da casca de batata inglesa na produção de farinha para elaboração de biscoitos.

\section{Material e métodos}

\subsection{Obtenção da farinha de casca de batata inglesa (Solanum tuberosum $L$.)}

As batatas foram selecionadas entre as de melhor aspecto, levando-se em conta a aparência. A produção da farinha foi realizada de acordo com a metodologia utilizada por FERNANDES (2006), com a lavagem das cascas de batatas em água corrente, para que fossem retiradas sujeiras e impurezas, e mergulhadas em solução de hipoclorito de sódio na concentração de 20 mg/L, por 10 minutos. As cascas foram acondicionadas e uniformemente distribuídas em camada fina em bandejas e depois colocadas em estufa com circulação de ar a $70{ }^{\circ} \mathrm{C}$ por 24 horas.

A farinha (Figura 1) foi elaborada em planta piloto do Departamento de Engenharia de Alimentos, embalada em sacos de polietileno para evitar contato com o ar e armazenado em temperatura ambiente. 
Figura 1. Farinha de Casca de Batata inglesa.

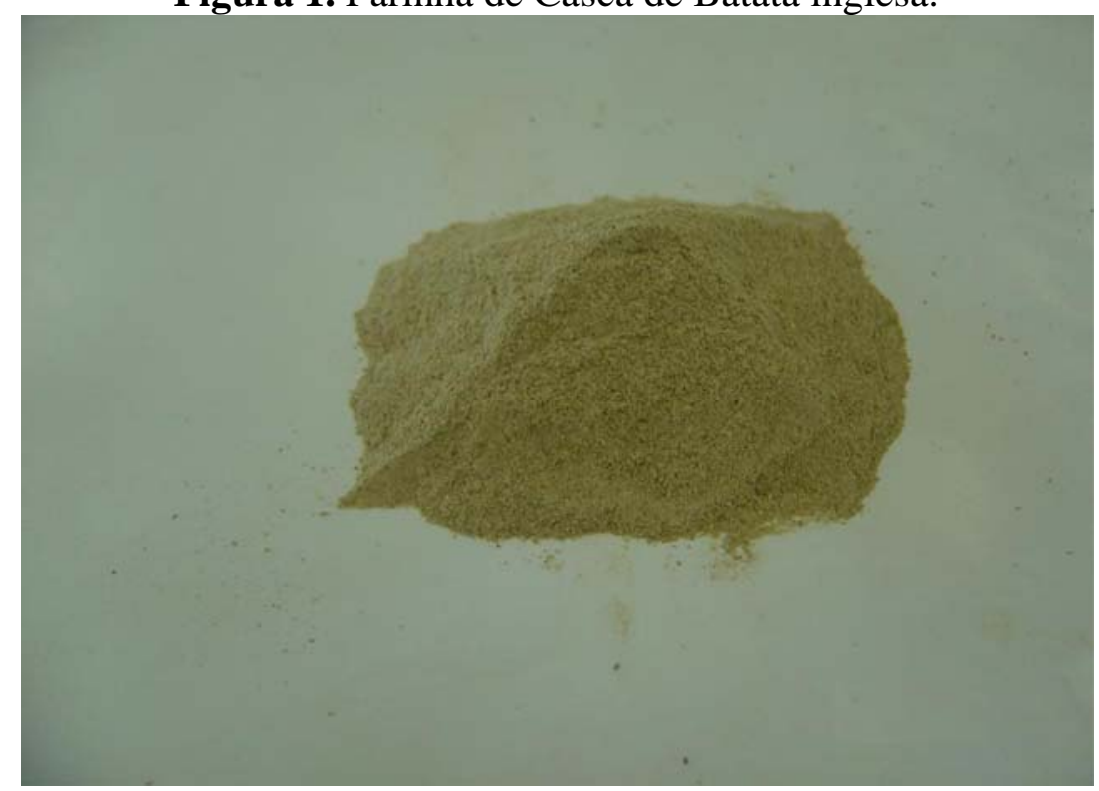

Fonte: Autor

A descrição das etapas da produção de farinha de casca de batata inglesa está apresentada na Figura 2.

Figura 2 Fluxograma para obtenção da farinha de casca de batata.

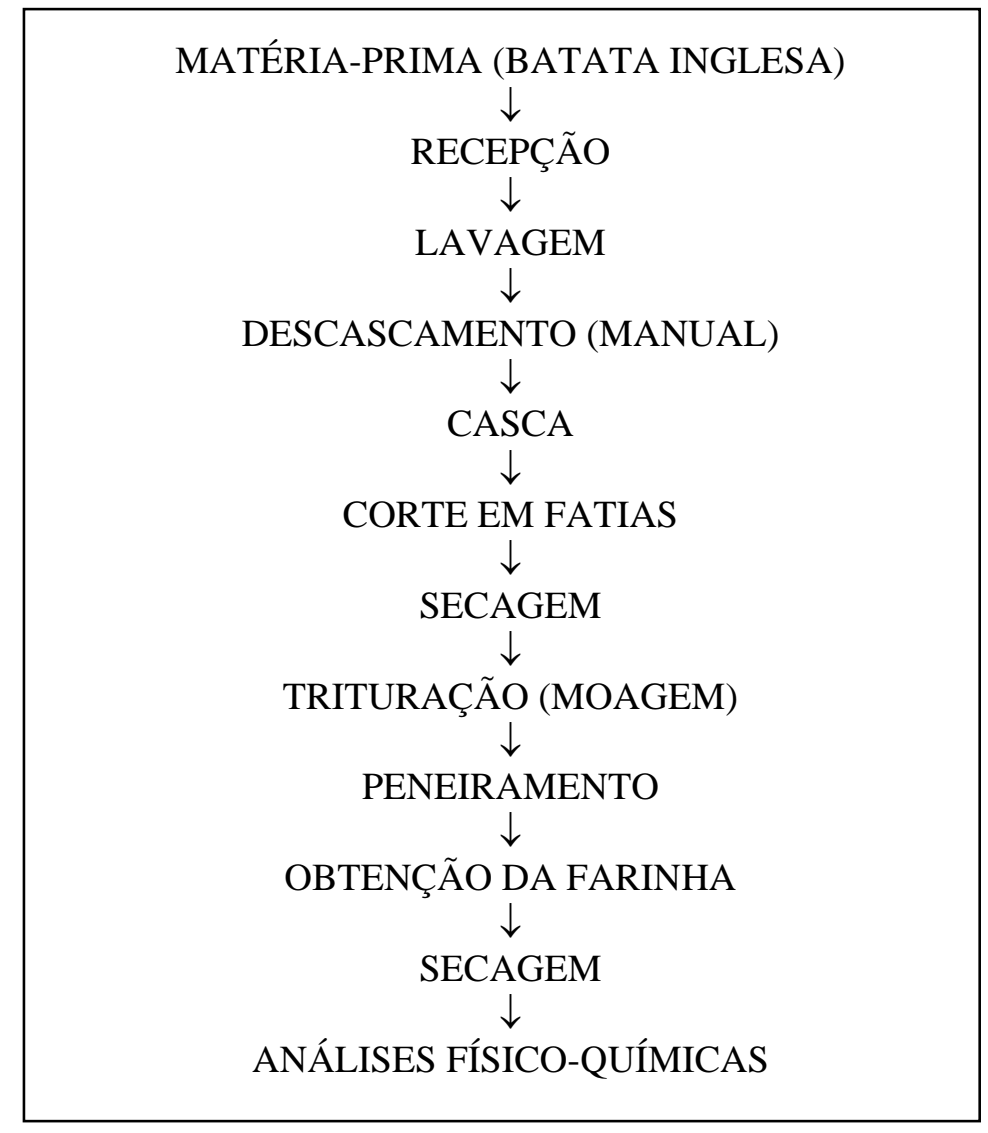




\subsection{Obtenção dos biscoitos com farinha de casca de batata}

A elaboração dos biscoitos com a adição de farinha de casca de batata foi desenvolvida na usina Piloto de Panificação do Departamento de Engenharia de Alimentos na Universidade Estadual do Centro-Oeste e suas etapas estão representadas na Figura 3.

De acordo com os testes realizados foram elaborados formulações de biscoitos com diferentes concentrações de farinha de casca de batata inglesa (5\%, 10\% e 20\%), a partir das quais foram feitas análises físico-químicas e sensorial. As três formulações de biscoitos elaborados com farinha de casca de batata são mostradas na Tabela 1 , considerando que a soma das massas de farinha totalizam $100 \%$ e os outros ingredientes são mensurados em relação a massa total de farinha empregada na formulação.

Tabela 1 - Formulações dos biscoitos elaborados com farinha de casca de batata inglesa.

Formulação 1 Formulação 2 Formulação 3

\begin{tabular}{cccc} 
Ingredientes & $(\%)$ & $(\%)$ & $(\%)$ \\
\hline Farinha de trigo & 95 & 90 & 80 \\
Farinha de casca de batata inglesa & 5 & 10 & 20 \\
Ovos & 40 & 40 & 40 \\
Gordura & 80 & 80 & 80 \\
Fermento Químico & 3 & 3 & 3 \\
Açúcar & 48 & 48 & 48 \\
Açúcar Mascavo & 43,5 & 43,5 & 43,5 \\
Sal & 0,5 & 0,5 & 0,5 \\
\hline
\end{tabular}

Figura 3. Fluxograma para elaboração do biscoito com farinha de casca de batata.

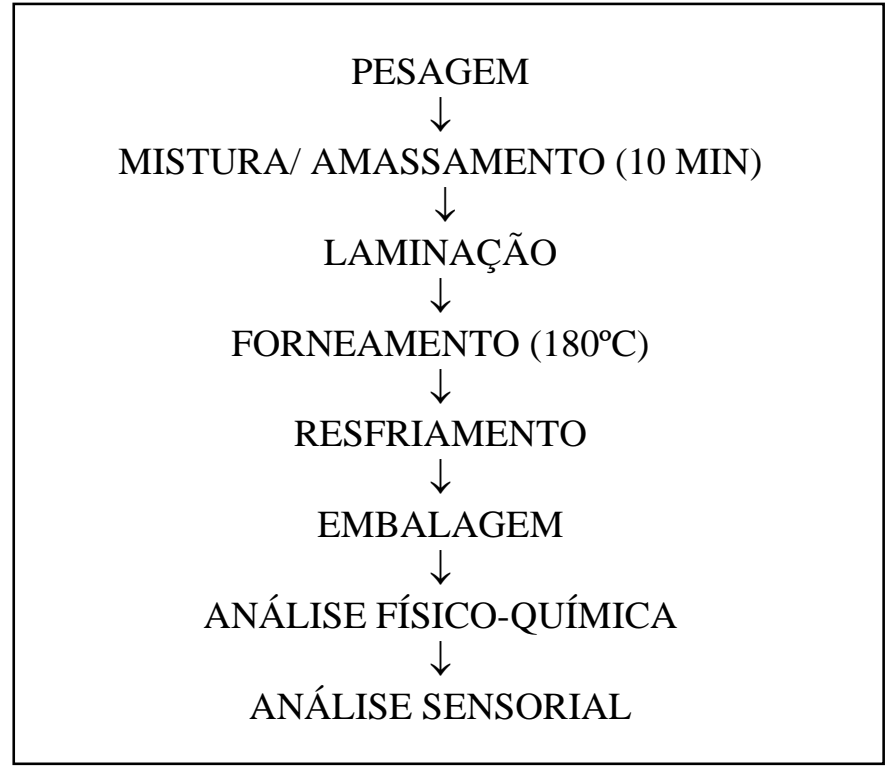




\subsection{Análises físico-químicas}

A farinha de casca de batata inglesa foi caracterizada em relação à umidade, cinzas, $\mathrm{pH}$, fibra bruta, lipídeos e proteínas. As análises foram feitas conforme metodologia descrita pelo INSTITUTO ADOLF LUTZ (1985).

Para determinação da fração glicídica o método utilizado foi o cálculo por diferença segundo a equação:

$$
\text { \% F.G. }=100-(\mathrm{U}+\mathrm{EE}+\mathrm{P}+\mathrm{F}+\mathrm{C})
$$

Sendo $\mathrm{FG}=$ fração glicídica (\%), $\mathrm{U}=$ umidade, EE= extrato etéreo (\%); P= proteína (\%); F= fibra bruta (\%) e $\mathrm{C}=$ cinzas (\%), considerando a matéria integral, segundo método da AOAC (1990).

\subsection{Análise Sensorial}

As três amostras de biscoitos (5\%, 10\%, 20\% de farinha de casca de batata) foram submetidos à teste de aceitação, utilizando-se uma ficha com escala hedônica estruturada com 9 pontos, onde cada provador avaliou as amostras de acordo com o sabor, anotando quanto gostou ou desgostou dos pães segundo a metodologia descrita por DUTCOSKY (1996). O painel sensorial foi composto por 30 consumidores não treinados, recrutados entre alunos e funcionários da Universidade Estadual do Centro-Oeste, com faixa etária entre 17 e 40 anos. As amostras foram analisadas com quatro dias de fabricação. A avaliação da aceitação dos biscoitos elaborados com farinha de casca de batata foi realizada no Laboratório de Análise Sensorial do Departamento de Engenharia de Alimentos, em cabines individuais, iluminadas com luz vermelha. As amostras foram servidas em pratos brancos codificadas com números de três dígitos aleatórios.

\subsection{Análise estatística dos resultados}

Os dados de composição e aceitação sensorial dos pães foram analisados por Análise de Variância (Anova), de acordo com DUTCOSKY (1996).

\section{Resultados e discussão}

Na elaboração da farinha de casca de batata inglesa, na etapa de descascamento, além de se tirar toda a casca, foram retiradas as injúrias presentes nas batatas, para que a farinha se apresentasse mais segura quanto à qualidade microbiológica e química. Os biscoitos elaborados com farinha de casca de batata inglesa são mostrados na Figura 4. 
Na literatura não foi encontrada referência de características físico-químicas para farinha de casca de batata. Porém, na Tabela 2 está apresentada a comparação entre a composição físicoquímica farinha de casca de batata inglesa com as farinhas de sabugo de milho, de trigo e de mandioca.

Figura 4 - Biscoitos elaborados com farinha de casca de batata inglesa.

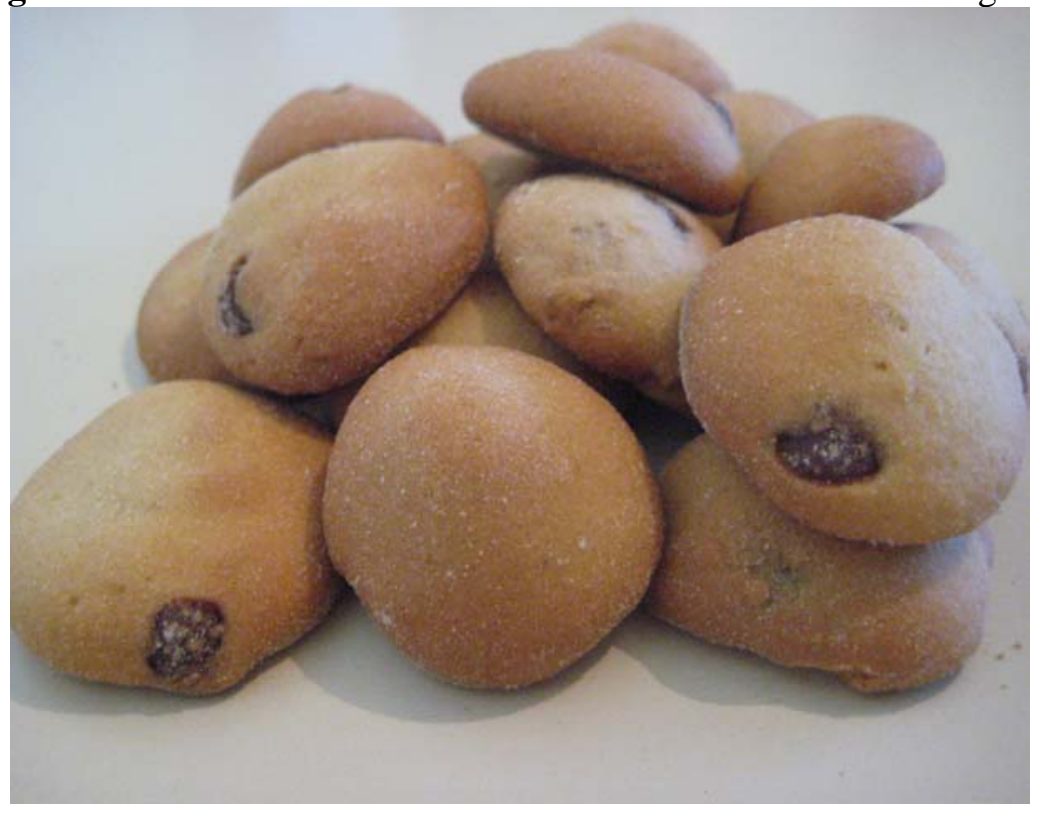

Tabela 2 - Características físico-químicas da farinha de casca de batata, trigo, mandioca e sabugo de milho (dados expressos em \% exceto para o $\mathrm{pH}$ )

Farinhas

\begin{tabular}{ccccc}
\cline { 2 - 5 } Parâmetros & $\begin{array}{c}\text { de trigo } \\
\text { de Sabugo de milho } \\
\text { (ZIGLIO et al., 2007) }\end{array}$ & $\begin{array}{c}\text { de mandioca } \\
\text { (BRASIL, } \\
\text { 1978) }\end{array}$ & $\begin{array}{c}\text { (ZIGLIO et al., } \\
\text { 2007) }\end{array}$ & de casca de batata \\
\hline Umidade & 8,9 & 13 & 12,5 & 6,5 \\
Cinzas & 2,3 & 0,4 & 1,3 & 7,3 \\
pH & 7,0 & $\mathrm{Nd}^{*}$ & $\mathrm{Nd}^{*}$ & 5,7 \\
Lipídeos & $\mathrm{Nd} *$ & $\mathrm{Nd}^{*}$ & $\mathrm{Nd}^{*}$ & 2,5 \\
Fibras & 32,2 & 4,0 & 9,2 & 4,6 \\
Proteína & 2,5 & 8,3 & 8,5 & 2,5 \\
\hline
\end{tabular}

* Não detectado

A farinha de casca de batata obteve um teor de umidade de 6,5\%, como descrito na Tabela 2, teor este conforme os teores de umidade das farinhas especificadas pela ANVISA, que variam de 8 a 15\%. Em relação ao teor de proteínas a farinha de casca de batata apresentou o valor de 2,5\%, resultado dentro dos parâmetros das farinas apresentadas na legislação da CNNPA - ANVISA (BRASIL, 2008) que variam de 1,3 a 47\%. 
Em relação ao resíduo mineral (cinzas), obteve-se o valor de 7,34\%. Resultado fora dos parâmetros das farinhas apresentadas pela CNNPA - ANVISA (BRASIL, 2008) que variam de 1,0 a $6,0 \%$.

O teor de fibras, 4,6\%, apresentou-se alto quando comparado com os resultados do IBGE (1999) para farinha de trigo (80\% de extração), de 0,5\%. Esse alto teor de fibras permite que essa farinha seja enquadrada na categoria de alimentos “fonte de fibras” (BRASIL, 2008).

Os resultados obtidos nas análises físico-químicas do biscoito elaborado com 5\% de farinha de casca de batata inglesa estão apresentados na Tabela 3.

O biscoito de elaborado com farinha de casca de batata inglesa apresentou o valor de umidade de $10,2 \%$ e de cinzas de $0,003 \%$, dentro dos padrões apresentados pela ANVISA (BRASIL, 2008) com valor máximo de umidade e cinzas de 14\% e 3\%, respectivamente.

Tabela 3 - Características físico-químicas do biscoito (dados expressos em \% exceto pH).

\begin{tabular}{|c|c|c|}
\hline Parâmetros & $\begin{array}{l}\text { Valor Teórico para Biscoito } \\
\text { Doce segundo IBGE (1999) }\end{array}$ & $\begin{array}{c}\text { Biscoito elaborado com } \\
\text { farinha de casca de batata * }\end{array}$ \\
\hline Umidade & 8,4 & $10,2 \pm 0,366$ \\
\hline Cinzas & 0,7 & $0,003 \pm 0,0005$ \\
\hline $\mathrm{pH}$ & $\mathrm{Nd}^{* *}$ & $6,7\left(20,5^{\circ} \mathrm{C}\right)$ \\
\hline Lipídeos & 7,8 & $6,1 \pm 0,421$ \\
\hline Fibras & 0,5 & $3,1 \pm 0,003$ \\
\hline Proteína & 9,0 & $8,3 \pm 0,29$ \\
\hline Carboidratos & 74,1 & $72,29 \pm 0,05$ \\
\hline
\end{tabular}

* Valores médios de duas repetições com duas determinações cada uma \pm desvio padrão.

**Não detectado.

Na Tabela 4 está apresentada os resultados do teste de aceitação com as médias das notas atribuídas pelos provadores para cada uma das três formulações de biscoito com 5, 10 e 20\% de farinha de casca de batata. Cada formulação foi avaliada por 30 julgadores. Os resultados obtidos na análise sensorial foram avaliados estatisticamente pela análise de variância.

Tabela 4 - Resultados das médias do teste de aceitação.

Farinha de casca de batata inglesa

$\begin{array}{ll}5 \% & 6,97 a \\ 10 \% & 6,67 a \\ 20 \% & 6,43 a\end{array}$

* Letras iguais indicam que não há diferença significativa entre as médias. 
Na Tabela 5 está mostrado os resultados da análise de variância aplicada ao teste de escala hedônica estruturada de bicoitos elaborados com 5\%, 10\%, 20\% de farinha de casca de batata, onde se observa que não há diferença significativa nos níveis de significancia de $1 \%$ e $5 \%$, entre as formulações avaliadas.

Tabela 5 - Resumo de análise de variância do teste de escala hedônica.

\begin{tabular}{ccccc}
\hline $\mathbf{C V}$ & GL & SQ & QM & F \\
\hline Amostra & 2 & 4,29 & 2,14 & 2,64 \\
Provador & 29 & 99,96 & 3,45 & \\
Resíduo & 58 & 47,04 & 0,81 & \\
Total & 89 & 151,29 & 1,70 & \\
\hline
\end{tabular}

Nomenclatura: $\mathrm{GL}=$ graus de liberdade; $\mathrm{SQ}=$ soma dos quadrados; $\mathrm{QM}=$ quadrado médio; $\mathrm{F}=\mathrm{F}$ calculado; $\mathrm{F}_{\text {tabela }} 5 \%=3,16 ; \mathrm{F}_{\text {tabela }} 1 \%=5,0$

A resposta do teste de aceitação das três formulações de biscoitos investigadas com 5\%, $10 \%$ e $20 \%$ de farinha de casca de batata inglesa foram de 77,4\%, 74,1\% e 71,4\% de aceitação, respectivamente.

\section{Conclusão}

Nas condições experimentais, a produção de biscoitos com farinha de casca de batata, mostrou-se viável no que diz respeito à aceitabilidade do produto. Os biscoitos com 5\%, 10\% e 20\% de farinha de casca de batata tiveram uma boa aceitação pelos julgadores, sendo que a mesma não se distinguiu estatisticamente no nível de significância de $1 \%$ e 5 \%. Portanto, o biscoito elaborado com farinha de casca de batata pode ser considerado um produto de qualidade e viável para aumentar o valor agregado do subproduto casca de batatas, além de eliminar problemas devido ao impacto desse subproduto no meio ambiente. Além disso, o biscoito elaborado com 5\% de farinha casca de batata inglesa apresentou em sua composição 8,3\% de fibra bruta, o que diferencia este produto dos demais pelo fato de ter esse atrativo nutricional. O teor de fibras da farinha de casca de batata inglesa foi de 4,6\%, o que permite enquadrá-la na categoria de alimentos “fonte de fibras”.

\footnotetext{
Abstract

Front to the importance of the use of residues in the industry, the present article had for objective to study the cookie elaboration with addition of residues (flour of potato peel (Solanum tuberosum L.)). They were prepared three formulations (5, 10 and 20\%), being varied the amount of flour of potato peel added to the basic formulation of the cookie. In the physiochemical analyses of the flour they were obtained values $6,50 \% ; 7,34 \% ; 5,72 ; 2,49 \% ; 4,64 \%$ and 2,46\% for humidity, ashes, $\mathrm{pH}$,
} 
lipids, tenor of fibers and proteins, respectively, of the flour of potato peel. In the sensorial analysis, there was not significant difference in the in the levels of significance of $1 \%$ and $5 \%$. The cookie with $5 \%$ had values of $10,2 \% ; 0,003 \% ; 6,71 ; 6,1 \% ; 3,1 \% ; 72,29 \%$ and $8,3 \%$ for humidity, ashes, $\mathrm{pH}$, lipids, rude tenor of fibers, carbohydrate and proteins respectively.

Key words: cookie, flour of peel of potato, residues.

\section{Referências}

A.O.A.C. ASSOCIATION OF OFFICIAL AND AGRICULTURAL CHEMISTRY. Official Methods of Analysis. 5th edição. Washington, D.C. EUA, 1990.

BRASIL, Ministério da Saúde, Agência Nacional de Vigilância Sanitária. Resolução - RDC n¹2, de 24 de julho de 1978. Aprova NORMAS TÉCNICAS ESPECIAIS, do Estado de São Paulo, revistas pela CNNPA, relativas a alimentos (e bebidas), para efeito em todo território brasileiro.. Diário Oficial da República Federativa do Brasil, Brasília. Disponível em <http:// www.anvisa.gov.br/e-legis > Acesso em 14 dez 2008.

BRASIL, Ministério da Saúde, Agência Nacional de Vigilância Sanitária. Resolução - RDC n²7, de 13 de janeiro de 1998. Aprova REGULAMENTO TÉCNICO REFERENTE A INFORMAÇÃO NUTRICIONAL COMPLEMENTAR. Diário Oficial da República Federativa do Brasil, Brasília. Disponível em <http:// www.anvisa.gov.br/e-legis > Acesso em 14 dez 2008

DASH, A. EL.; GERMANI, R. Tecnologia de farinhas mistas na produção de biscoitos. Brasília: EMBRAPA.v.6.1994.47p.

DUTCOSKY, S. D. Análise Sensorial de Alimentos. Curitiba: Ed. Universitária Champagnat, 123 p, 1996.

FERNANDES, A.F. Utilização de farinha de casca de batata inglesa (Solanum tuberosum L.) na elaboração de pão integral. Dissertação (mestrado). Universidade Federal de Lavras. UFLA. Lavras. 2006.

FILGUEIRA, F. A. R. Novo Manual de olericultura: agrotecnologia moderna na produção e comercialização de hortaliças. Viçosa: UFV, 2000.

IBGE. Instituto Brasileiro de Geografia e Estatística. Estudo nacional da despesa familiar: tabela de composição de alimentos. 5. ed. Rio de Janeiro, 1999.

INSTITUTO ADOLF LUTZ, Determinações gerais. Normas analíticas do Instituto Adofo Lutz. $3^{\mathrm{a} e d, ~ S a ̃ o ~ P a u l o, ~}$ 1985, V.1.

SÃO PAULO. Secretaria Municipal do Abastecimento - SEMB. Hortaliças. São Paulo,2003. Disponível em: http://www.prodam.sp.gov.br/semab/dicas/desbatata.htm. Acesso em 11 nov.2003.

ZIGLIO, B. R.; BEZERRA, J. R. M. V.; BRANCO, I. G.; RIGO, M.; BASTOS, R. Elaboração de pães com adição de farinha de sabugo de milho. Revista Ciências Exatas e Naturais, Vol.9 nº 1, Jan/Jun, p. 115-128, 2007.

Nome : Tábata Tayara Garmus

Filiação institucional: Universidade Estadual do Centro-Oeste (UNICENTRO)

Departamento: Acadêmica do Curso de Engenharia de Alimentos

Bolsista de Iniciação Científica

Endereço completo para correspondência (bairro, cidade, estado, país e CEP):

CAIXA POSTAL 3010 - Guarapuava/PR - Brasil - CEP: 85010-990

Telefone: (42) 36298128

Nome: José Raniere Mazile Vidal Bezerra

Filiação institucional: Universidade Estadual do Centro-Oeste (UNICENTRO)

Departamento: Departamento de Engenharia de Alimentos (DEALI)

Titulação: Doutor em Engenharia de Alimentos

Endereço completo para correspondência (bairro, cidade, estado, país e CEP):

CAIXA POSTAL 3010 - Guarapuava/PR - Brasil - CEP: 85010-990

Telefone: (42) 99229906 
e-mail: raniere@unicentro.br

Nome: Maurício Rigo

Filiação institucional: Universidade Estadual do Centro-Oeste (UNICENTRO)

Departamento: Departamento de Engenharia de Alimentos (DEALI)

Titulação: Doutor em Engenharia de Alimentos

Endereço completo para correspondência (bairro, cidade, estado, país e CEP):

CAIXA POSTAL 3010 - Guarapuava/PR - Brasil - CEP: 85010-990

Telefone: (42) 88035144

e-mail: mauriciorigo@yahoo.com.br

Nome: Katielle Rosalva Voncik Córdova

Filiação institucional: Universidade Federal do Paraná (UFPR)

Titulação: Doutoranda do Programa de Pós-Graduação em Tecnologia de Alimentos (PPGTA)

Mestre em Tecnologia de Alimentos

Endereço completo para correspondência (bairro, cidade, estado, país e CEP):

CAIXA POSTAL 19011 - Curitiba/PR - Brasil - CEP: 81531-990

Telefone: (41) 33613232

e-mail: kvcordova@hotmail.com 